\title{
Fungos isolados da água, ração e cama aviária de frangos de corte da região da zona da mata do Estado de Alagoas, Brasil
}

Fungi isolated from water, feed and poultry litter of broiler chickens in the zona da mata region of the State of Alagoas, Brazil

Hongos aislados de agua, pienso y cama de aves de pollos de engorde en la zona forestal del Estado de Alagoas, Brasil

\section{Resumo}

A cama aviária tem importância na epidemiologia de infecções fúngicas, qualidade ambiental dos galpões e no desempenho zooeconômico das aves. O objetivo deste estudo foi identificar e quantificar a ocorrência de fungos na água, ração e cama aviária de frangos de corte da região da zona da mata, estado de Alagoas, Brasil. Para isso, foram realizadas coletas em aviários tratados com amônia e iodo em 4 momentos diferentes. Da água e da ração foram coletadas $30 \mathrm{~mL}$ e $30 \mathrm{~g}$, respectivamente, dos bebedouros e comedouros das aves em recipientes estéreis. Na cama aviária, as amostras foram coletadas através da técnica de $s w a b$ de arrasto e $10 \mathrm{~g}$ direto da cama, resultando em 298 amostras nos diferentes locais analisados. Posteriormente, as amostras foram cultivadas em ágar Sabouraud dextrose acrescido de cloranfenicol e incubadas a temperatura ambiente por 7 a 15 dias. Em seguida, foi realizado isolamento, purificação, microcultivo e identificação dos fungos. Das 298 amostras avaliadas, foram obtidas 24.221 Unidades Formadoras de Colônias (UFC), sendo 13.801 (57,0\%) correspondentes a fungos filamentosos e $10.420(43,0 \%)$ a fungos leveduriformes. Na cama aviária foram encontradas $18.996(78,0 \%)$ UFC, dentre as quais $9.713(40,0 \%)$ foram provenientes do composto da cama e $9.283(38,0 \%)$ resultantes do swab de arrasto, enquanto na ração e na água foram obtidas $4.152(17,0 \%)$ e $1.076(5,0 \%)$ UFC, respectivamente. O gênero de maior ocorrência foi Saccharomyces spp. (16,6\%), seguido por Fusarium spp. (12,2\%) e Acremonium spp. (11,0\%). Esses achados evidenciam a necessidade de 
medidas de controle microbiológico nos locais amostrados, de modo a garantir melhores condições de bem-estar e saúde para aves e seres humanos.

Palavras-chave: Fungos; Aviários; Frangos de corte.

\begin{abstract}
Avian litter is important in the epidemiology of fungal infections, environmental quality of the sheds and in the zooeconomic performance of the birds. The objective of this study was to identify and quantify the occurrence of fungi in the water, feed and poultry litter of broilers in the region of the forest zone, state of Alagoas, Brazil. For this, collections were carried out in aviaries treated with ammonia and iodine at 4 different times. From the water and the feed, $30 \mathrm{~mL}$ and $30 \mathrm{~g}$ were collected, respectively, from the drinking fountains and bird feeders in sterile containers. In the avian litter, the samples were collected using the drag swab technique and $10 \mathrm{~g}$ straight from the bed, resulting in 298 samples in the different analyzed sites. Subsequently, the samples were grown on Sabouraud dextrose agar plus chloramphenicol and incubated at room temperature for 7 to 15 days. Then, isolation, purification, microculture and identification of fungi were performed. Of the 298 samples evaluated, 24,221 Colony Forming Units (CFU) were obtained, 13,801 (57.0\%) corresponding to filamentous fungi and 10,420 (43.0\%) to yeast-like fungi. In the avian litter 18,996 (78.0\%) CFU were found, among which 9,713 (40.0\%) came from the litter compound and 9,283 $(38.0 \%)$ resulted from the drag swab, while in the feed and water 4,152 (17.0\%) and 1,076 (5\%) UFC, respectively. The most common genus was Saccharomyces spp. (16.6\%), followed by Fusarium spp. (12.2\%) and Acremonium spp. (11.0\%). These findings demonstrate the need for microbiological control measures in the sampled places, in order to ensure better conditions of well-being and health for birds and humans.
\end{abstract}

Keywords: Fungi; Aviaries; Broiler chickens.

\title{
Resumen
}

La basura aviar es importante en la epidemiología de las infecciones fúngicas, la calidad ambiental de los galpones y en el desempeño zooeconómico de las aves. El objetivo de este estudio fue identificar y cuantificar la ocurrencia de hongos en el agua, alimento y cama de aves de pollos de engorde en la región de la zona forestal, estado de Alagoas, Brasil. Para ello, las recolecciones se realizaron en aviarios tratados con amoniaco y yodo en 4 tiempos diferentes. Del agua y del alimento se recolectaron $30 \mathrm{~mL}$ y $30 \mathrm{~g}$, respectivamente, de los bebederos y comederos de pájaros en recipientes estériles. En la camada de aves, las muestras se recolectaron mediante la técnica de arrastre con hisopo y $10 \mathrm{~g}$ directamente del lecho, dando como resultado 298 muestras en los diferentes sitios analizados. Posteriormente, las muestras se cultivaron en agar dextrosa Sabouraud más cloranfenicol y se incubaron a temperatura ambiente durante 7 a 15 días. En seguida, se realizó el aislamiento, purificación, microcultivo e identificación de hongos. De las 298 muestras evaluadas, se obtuvieron 24,221 Unidades Formadoras de Colonias (UFC), 13,801 (57.0\%) correspondientes a hongos filamentosos y 10,420 (43.0\%) a hongos levaduriformes. En la camada aviar se encontraron 18,996 (78.0\%) UFC, de las cuales 9,713 (40.0\%) procedieron del compuesto de la cama y 9,283 (38.0\%) resultaron del raspado, mientras que en pienso y agua 4,152 (17.0\%) y 1,076 (5.0\%) UFC se obtuvieron, respectivamente. El género más común fue Saccharomyces spp. (16,6\%), seguido de Fusarium spp. (12,2\%) y Acremonium spp. (11,0\%). Estos hallazgos demuestran la necesidad de medidas de control microbiológico en los lugares muestreados, a fin de garantizar mejores condiciones de bienestar y salud para las aves y los seres humanos.

Palabras clave: Hongos; Aviarios; Pollos de engorde.

\section{Introdução}

O Brasil é o maior exportador e o segundo maior produtor de frangos de corte do mundo (Macedo et al., 2019). Essa produção intensa e contínua necessita de instalações avícolas que promovam alojamento confortável para esses animais, que geralmente estão acomodados em galpões ou estábulos e que possuem como leito cama de aviário (Oliveira et al., 2018).

Cama de aviário corresponde a todo e qualquer material depositado no chão e que sirva de leito para as aves, como também receber excreções, restos de rações e penas. Tem como função evitar o contato da ave com o chão, absorvendo umidade, incorporando resíduos, proporcionando bem-estar e melhorando o conforto. Vários são os materiais que podem ser utilizados na constituição desses ambientes, desde os mais comuns, como casca de arroz, maravalha ou serragem, até alguns alternativos como bagaço-de-cana (Staub et al., 2017).

O fato da produção de frangos acontecer em sistemas com alta densidade animal, possibilitam condições favoráveis à ocorrência, disseminação e multiplicação de patógenos, constituindo um problema ambiental e de saúde pública (Silva et al., 2012; Melo et al., 2018), onde os empastamentos localizados, tornam-se meios propícios ao desenvolvimento de fungos patogênicos (Vilela et al., 2004). 
Entre os principais gêneros de fungos causadores de doenças nas aves destacam-se Aspergillus sp., Penicillium sp., e Candida sp., que promovem diferentes quadros clínicos com manifestações variadas, sobressaindo a forma respiratória, que afeta especialmente os pulmões e sacos aéreos, e em menor proporção o sistema nervoso central, olhos e sistema digestivo (Radwan et al., 2018; Sugiharto, 2019). Quanto aos processos micóticos que acometem seres humanos e aves, destaca-se a candidíase (Miragliota et al., 2002; Radwan et al., 2018) e no caráter ocupacional, a histoplasmose e a criptococose (Chen \& Jiang, 2014; Skóra et al., 2016; Asfaw \& Dawit, 2017).

Dada a importância dos fungos na ocorrência de infecções, tanto para animais quanto para seres humanos que manipulam e se submetem ao contato direto com excrementos dos galináceos, essa pesquisa justifica a necessidade de se identificar quais agentes fúngicos estão presentes nos diferentes substratos do ambiente de aviários. A identificação das possíveis fontes de infecções possibilitará a elaboração de protocolos preventivos para esses criatórios. Diante do exposto, o objetivo deste estudo foi determinar a ocorrência de fungos na água, na ração e na cama aviária de frangos de corte em avícolas localizadas na zona da mata do estado de Alagoas, Brasil.

\section{Metodologia}

\subsection{Local de estudo}

O presente estudo experimental de cunho quantitativo foi realizado em quatro aviários de frangos de corte da região da Zona da Mata do estado de Alagoas, Brasil, localizados no município de Pilar, com latitude de -09:35:50 ao Sul, longitude 35:57:24 a Oeste e altitude de 13 metros.

\subsection{Coleta e processamento das amostras}

Foram coletadas 298 amostras, sendo 48 da água, 48 da ração e 202 da cama aviária (170 do composto da cama aviária e 32 coletadas com swabs de arrasto), a qual é formada por bagaço de cana, sendo três galpões aviários tratados com amônia e apenas um com iodo, medindo 30x10m e 60x8m, respectivamente.

Nos aviários de frangos de corte foram realizadas 4 coletas, com período de 42 dias e divididas em 4 momentos. A $1^{\text {a }}$ coleta foi realizada no momento 0 (M0), no qual a cama aviária é colocada no galpão e onde são introduzidos os pintos; a $2^{\mathrm{a}}$ coleta foi efetuada no $14^{\circ}$ dia (M14), no qual é realizado o tratamento da cama aviária, com amônia ou iodo; a $3^{\text {a }}$ coleta ocorreu no $28^{\circ}$ dia (M28); e a $4^{\text {a }}$ coleta no $42^{\circ}$ dia (M42), no qual os frangos são retirados para o abate. Durante as coletas foram aferidas a temperatura e umidade da cama aviária e do ambiente interno dos galpões.

\subsection{1 Água}

Para cada aviário foram coletadas aleatoriamente dos bebedouros três amostras de água nos 4 diferentes momentos, utilizando-se coletores de plástico estéreis com capacidade para $30 \mathrm{~mL}$, totalizando 48 amostras. De cada amostra coletada, retirou-se 0,5 mL e cultivou-se em placas de Petri contendo Ágar Sabouraud Dextrose (ASD) acrescido de cloranfenicol. Em seguida, as placas foram incubadas a temperatura ambiente $\left(28^{\circ} \pm 2^{\circ} \mathrm{C}\right)$ por 7 a 15 dias, até o surgimento de colônias. Os experimentos foram realizados em duplicata.

\subsubsection{Ração}

Dos comedouros foram coletadas aleatoriamente três amostras, com o auxílio de coletores de plástico estéreis contendo aproximadamente $30 \mathrm{~g}$ de ração, totalizando 48 amostras. Para o processamento, foram retirados $10 \mathrm{~g}$ de cada recipiente e transferidos para tubos de vidro contendo $90 \mathrm{~mL}$ de água destilada estéril. As suspensões resultantes foram agitadas em vórtex durante três minutos e mantidas em repouso por 30 minutos à temperatura ambiente para promover a sedimentação 
dos resíduos e permitir a flutuação das estruturas fúngicas. Transcorrido esse tempo, alíquotas de 0,5 mL foram cultivadas em placas de Petri contendo ASD com cloranfenicol $(50 \mathrm{mg} / \mathrm{L})$, em duplicata. As placas foram incubadas à temperatura ambiente $\left(28^{\circ} \pm 2^{\circ} \mathrm{C}\right)$ por 7 a 15 dias.

\subsubsection{Cama aviária}

Foram coletadas 2 amostras da cama aviária através da técnica de swab de arrasto, em todos os aviários nos diferentes momentos, totalizando 32 amostras. A técnica consiste em arrastar o swab umedecido em água destilada estéril por toda a superfície da cama aviária durante 20 minutos. Posteriormente, os swabs foram acondicionados em tubos contendo água destilada estéril. De cada tubo, foram aspiradas alíquotas de $0,5 \mathrm{~mL}$ e cultivadas na superfície de placas de Petri contendo ASD com cloranfenicol $(50 \mathrm{mg} / \mathrm{mL})$, em duplicata.

Para o isolamento de fungos do composto da cama aviária, foram coletadas 10 amostras em pontos aleatórios distribuídos ao longo de cada aviário, utilizando-se espátulas e frascos plásticos estéreis. De cada recipiente foram retirados $10 \mathrm{~g}$ da amostra e, em seguida, transferidas para frascos contendo $90 \mathrm{~mL}$ de água destilada estéril. As suspensões obtidas foram agitadas em vórtex por 3 minutos e mantidas em repouso por 30 minutos, dispondo posteriormente alíquotas de 0,5 ml em placas de Petri contendo ASD com cloranfenicol, em duplicata. Para ambos os procedimentos, as amostras foram incubadas à temperatura ambiente por 7 a 15 dias $\left(28^{\circ} \pm 2^{\circ} \mathrm{C}\right)$.

\subsection{Isolamento e identificação dos fungos}

Após constatação de crescimento fúngico, as placas foram submetidas a análise quantitativa, realizada a partir da contagem do número de Unidades Formadoras de Colônias (UFC) existentes nas amostras, e contagem diferencial, classificando as colônias em leveduriformes e filamentosas.

As colônias fúngicas distintas (características macroscópicas) foram purificadas através da técnica de esgotamento por estrias em placas de Petri contendo ASD e incubadas a $28 \pm 2{ }^{\circ} \mathrm{C}$ durante três dias. Após a purificação, as amostras foram transferidas para Ágar Batata Dextrose (BDA) contido em tubos de ensaio para manutenção dos isolados e posterior identificação.

A identificação foi realizada por meio da observação de características macroscópicas (textura, coloração e diâmetro das colônias) e microscópicas (microestruturas) (Hoog et al., 2000; Lacaz et al., 2002; Sidrim \& Rocha, 2010; Zaitz et al., 2010). Para facilitar o processo de identificação e melhorar a visualização de estruturas dos fungos filamentosos, realizou-se microcultivo em lâmina, através da técnica descrita por Riddell (1950), utilizando-se ágar Lactrimel para estimular a esporulação.

Os fungos leveduriformes foram identificados por meio de análise macroscópica das colônias em ASD e microscópica por meio da técnica de microcultivo em ágar fubá. As características observadas foram associadas aos testes de assimilação e fermentação de fontes de carbono e nitrogênio, bem como outros ensaios fenotípicos (Zaitz et al., 2010).

Após identificação, os fungos isolados foram preservados sob óleo mineral (Sidrim \& Rocha, 2010).

\section{Resultados e Discussão}

Das 298 amostras avaliadas, foram obtidas 24.221 UFC, sendo 13.801 (57\%) correspondentes a fungos filamentosos e $10.420(43 \%)$ a fungos leveduriformes. Com relação aos diferentes substratos analisados, na cama aviária foram obtidas 18.996 UFC (78\%), das quais 9.713 (40\%) foram provenientes do composto da cama e 9.283 (38\%) resultantes de swabs de arrasto, seguidos pela ração com 4.149 (17\%) e água com 1.076 (5\%). A contagem global de colônias nos momentos "M0", 
"M14", "M28" e "M42", resultou em 6.886 (28,4\%), 5.384 (22,2\%), 4.515 (18,7\%) e 7.436 (30,7\%) UFC, respectivamente. No dia 28 verificou-se uma menor tendência para o isolamento de leveduras, conforme observado na Tabela 1.

Tabela 1. Distribuição total de Unidades Formadoras de Colônias obtidas da ração, da água e da cama aviária de frangos de corte, obtidas nos diferentes momentos da coleta.

\begin{tabular}{|c|c|c|c|c|c|c|c|c|c|}
\hline \multirow{3}{*}{$\begin{array}{l}\text { Momento das } \\
\text { coletas }\end{array}$} & \multirow{2}{*}{\multicolumn{2}{|c|}{ Ração }} & \multirow{2}{*}{\multicolumn{2}{|c|}{ Água }} & \multicolumn{4}{|c|}{ Cama Aviária } & \multirow{3}{*}{ Total de UFC } \\
\hline & & & & & \multicolumn{2}{|c|}{ Swab } & \multicolumn{2}{|c|}{ Composto } & \\
\hline & $\mathbf{L}$ & $\mathbf{F}$ & $\mathbf{L}$ & $\mathbf{F}$ & $\mathbf{L}$ & $\mathbf{F}$ & $\mathbf{L}$ & $\mathbf{F}$ & \\
\hline M0 & 866 & 1.257 & 215 & 70 & 414 & 506 & 1.254 & 2.304 & 6.886 \\
\hline M14 & 130 & 415 & 286 & 119 & 1.372 & 515 & 874 & 1.673 & 5.384 \\
\hline M28 & - & 1.481 & 11 & 126 & 116 & 1.320 & 583 & 878 & 4.515 \\
\hline M42 & - & - & 30 & 219 & 3.068 & 1.972 & 1.201 & 946 & 7.436 \\
\hline Total & 996 & 3.153 & 542 & 534 & 4.970 & 4.313 & 3.912 & 5.801 & 24.221 \\
\hline
\end{tabular}

M0: momento zero; M14: momento quatorze; M28: momento vinte e oito; M42: momento quarenta e dois; L: leveduriformes; F: filamentosos; UFC: Unidades Formadoras de Colônias. Fonte: Autores.

De acordo com os resultados obtidos nesse estudo, a grande quantidade de fungos encontrados nos aviários pode ser justificada pela elevada diversidade microbiana presente no ambiente, o que corrobora com os achados da literatura, que caracterizam o setor avícola atual como propício para ocorrência de patógenos (Silva et al., 2012; Melo et al., 2018).

O clima tropical do Brasil também é um fator que propicia condições para a proliferação de fungos toxigênicos capazes de liberar micotoxinas no meio ocasionando doenças aos animais (Fraga et al., 2009). Nesse contexto, Fernandes (2004) ao avaliar os principais riscos da exposição a poeiras provenientes do trabalho em aviários, destacou os fungos como um dos principais agravos à saúde dos ocupantes.

A maior quantidade de fungos foi observada na cama em comparação a água e ração dos aviários. Segundo Paganini (2004), a cama aviária é uma importante fonte de contaminação para a propagação de doenças nas aves. Essa realidade pode estar relacionada com a grande quantidade de matéria orgânica disposta nesse ambiente, favorecendo o desenvolvimento de fungos. Há ainda a proximidade dos comedouros e dos bebedouros ao piso dos aviários, havendo constantemente o derramamento de ração e de água, que umedece o substrato favorecendo o crescimento de microrganismos.

Segundo Hernandez et al. (2002) dentre os fatores que podem afetar a proliferação de fungos na cama aviária, ressalta-se o tipo ou composição da ração, natureza e quantidade do material de cobertura do piso do galpão, período de permanência das aves sobre o material, excrementos das aves, número de aves por área, condições e período de estocagem, temperatura ambiente, utilização de equipamentos de resfriamento (nebulizadores e ventiladores), entre outros fatores.

Preconiza-se que a cama a ser utilizada nos aviários de reprodução e de corte seja de qualidade, para tanto, a análise deve ser efetuada sempre antes da acomodação dos galináceos no alojamento e em períodos durante a criação para os quais se evidenciar necessária, afinal o contato com os fungos presentes nesse local pode ser fonte de infecção para as aves (Rogeri et al., 2016).

Uma dieta com alta concentração de nutrientes e sais pode também aumentar a ingestão de água pelos frangos, acarretando no aumento de umidade da cama. Considerando que para cada unidade de alimento consumido os frangos bebem aproximadamente 1,75 unidades de água, retendo apenas 20\% dessa água para crescer (Bilgili et al., 2010), pode-se inferir que uma porção significativa de umidade é liberada para a cama. 
Quanto à quantidade de UFC encontrada na ração, esta pode estar relacionada ao armazenamento das rações no próprio aviário. Segundo Stringhin et al. (2000) a presença de fungos nas rações ou nos grãos pode representar importantes perdas em termos da qualidade nutricional, tornando o processo de descontaminação oneroso e difícil.

A menor quantidade de fungos encontrada nas amostras da água pode estar relacionada ao controle interno dos equipamentos. Portanto, o tipo e manejo dos bebedouros têm grande influência na umidade e qualidade da cama aviária (Meluzzi \& Sirri, 2009). Nesse sentido, a má regulagem do nível da água e pressão, altura e número insuficiente de equipamentos são causas frequentes de empastamento, proporcionando um aumento no crescimento de fungos.

No que se refere ao tratamento dos aviários, foi observada maior ocorrência de fungos no Aviário 2 tratado com amônia (5322 UFC), onde foi possível isolar 2639 UFC de fungos leveduriformes e 2683 UFC de fungos filamentosos. Em contrapartida, o aviário tratado com iodo apresentou a menor concentração de fungos (4292 UFC), mesmo possuindo maior dimensão estrutural, sendo 1616 UFC correspondentes a leveduras e 2676 UFC a fungos filamentosos, evidenciando melhor desinfecção do ambiente, especialmente sobre fungos leveduriformes. Com relação aos momentos das coletas na cama aviária, verificou-se uma maior concentração de fungos em M42 (7281 UFC), enquanto a menor concentração foi observada em M28 (2991 UFC), conforme evidenciado na Tabela 2.

Tabela 2. Distribuição de UFC de fungos filamentosos e leveduriformes nos aviários tratados com amônia e iodo nos diferentes momentos das coletas.

\begin{tabular}{cccccccccc}
\hline \multirow{2}{*}{$\begin{array}{c}\text { Momento das } \\
\text { coletas }\end{array}$} & \multicolumn{2}{c}{ A1 } & \multicolumn{2}{c}{ A2 } & \multicolumn{2}{c}{ A3 } & \multicolumn{2}{c}{ I } & \multirow{2}{*}{ Total } \\
\cline { 2 - 8 } & L & F & L & F & L & F & L & F & \\
\hline M0 & 151 & 760 & 306 & 633 & 511 & 743 & 331 & 761 & 4.196 \\
M14 & 402 & 853 & 574 & 894 & 418 & 455 & 418 & 514 & 4.528 \\
M28 & 143 & 407 & 363 & 655 & 251 & 673 & 338 & 161 & 2.991 \\
M42 & 1.613 & 495 & 1.396 & 501 & 1.138 & 369 & 529 & 1.240 & 7.281 \\
\hline TOTAL & $\mathbf{2 . 3 0 9}$ & $\mathbf{2 . 5 1 5}$ & $\mathbf{2 . 6 3 9}$ & $\mathbf{2 . 6 8 3}$ & $\mathbf{2 . 3 1 8}$ & $\mathbf{2 . 2 4 0}$ & $\mathbf{1 . 6 1 6}$ & $\mathbf{2 . 6 7 6}$ & $\mathbf{1 8 . 9 9 6}$ \\
\hline
\end{tabular}

M0: momento zero; M14: momento quatorze; M28: momento vinte e oito; M42: momento quarenta e dois; A1, A2 e A3: aviários tratados com amônia; I: aviário tratado com iodo; L: leveduriformes; F: filamentosos; UFC: Unidades Formadoras de Colônias. Fonte: Autores.

A adição de produtos químicos à ração ou à matéria-prima é atualmente o método mais difundido para o controle da população microbiana, tanto diretamente no alimento, quanto no trato intestinal das aves após a ingestão. Contudo, a amônia é um gás altamente irritante para as aves, causa estresse, leva à perda de peso e pode até provocar morte (Rogeri et al., 2016). Nesse sentido, Hernandez \& Cazetta (2001) verificaram que frangos expostos à amônia, dióxido de carbono e poeira por seis dias consecutivos, apresentaram perda significativa de cílios a partir do epitélio da porção superior da traqueia, acarretando em prejuízo por interferir no transporte de muco e eliminação de partículas de poeira pelas aves.

Este efeito também foi verificado por Miragliota et al. (2002), considerando ainda a irritação da mucosa das vias respiratórias, comprometendo o funcionamento do sistema mucociliar do trato aéreo superior, predispondo a entrada de diversos agentes de doença, as quais levam a um quadro comum, a aerossaculite. Meluzzi \& Sirri (2009) acrescentam ainda que a amônia pode ser um gás nocivo à saúde dos trabalhadores, ocasionando irritação nos olhos e no sistema respiratório. Dessa forma, torna-se essencial o controle rigoroso da amônia no ar dos galpões, principalmente em densidades elevadas e no período final de criação, haja vista a maior liberação deste gás pela cama aviária nestas situações (Hernandez et al., 2002).

$\mathrm{Na}$ Tabela 3 encontram-se os parâmetros físico-químicos avaliados durante as coletas. A temperatura apresentou variação de 22,0 a $30,0^{\circ} \mathrm{C}$ e a umidade entre 38 a $55 \%$ durante os diferentes momentos. A menor temperatura foi observada na 
cama sem tratamento no $\mathrm{M} 0\left(22,7^{\circ} \mathrm{C}\right)$ e maior na cama tratada com amônia no $42^{\circ}$ dia $\left(30,0^{\circ} \mathrm{C}\right)$. Verificou-se menor e maior umidade no M0, na cama sem tratamento (30\%) e na cama tratada com amônia (55\%), respectivamente.

Tabela 3. Parâmetros físico-químicos avaliados durante as coletas.

\begin{tabular}{|c|c|c|c|c|c|c|}
\hline \multirow{2}{*}{ Momento das coletas } & \multicolumn{3}{|c|}{ Temperatura $\left({ }^{\circ} \mathbf{C}\right)$} & \multicolumn{3}{|c|}{ Umidade (\%) } \\
\hline & S/T & TI & TA & $\mathrm{S} / \mathrm{T}$ & TI & TA \\
\hline M0 & 22,7 & 24,0 & 25,4 & 30 & 53 & 55 \\
\hline M14 & - & 29,8 & 29,8 & - & 44 & 38 \\
\hline M28 & - & 29,0 & 29,0 & - & 44 & 44 \\
\hline M42 & - & 27,0 & 30,0 & - & 38 & 42 \\
\hline
\end{tabular}

M0: momento zero; M14: momento quatorze; M28: momento vinte e oito; M42: momento quarenta e dois; ST: sem tratamento; TI: tratada com iodo; TA: tratada com amônia. Fonte: Autores.

Entre os fatores que propiciam ou favorecem a multiplicação de microrganismos desejáveis, podemos citar a temperatura ótima variando de $20^{\circ} \mathrm{C}$ a $32^{\circ} \mathrm{C}$. No entanto, essas condições também podem favorecer a multiplicação de microrganismos oportunistas indesejáveis, principalmente quando a cama é reutilizada para mais de um lote de frangos (Algabr et al., 2018).

Segundo Oliveira et al. (2006), a faixa de temperatura ideal para frangos de corte situa-se entre 18 e $26^{\circ} \mathrm{C}$. Neste estudo, a maior quantidade de fungos foi obtida quando a temperatura estava superior a $27^{\circ} \mathrm{C}$ e umidade acima de $35 \%$ no momento das coletas. De acordo com Paganini (2004), a cama com umidade e temperatura elevadas torna-se empastada, proporcionando situação de desconforto às aves, diminuindo a resistência as doenças. Em ambientes com temperaturas acima de $27^{\circ} \mathrm{C}$, as aves aumentam sua produção de calor e a exigência de energia necessária para manter os mecanismos de resfriamento corporal, resultando na ocorrência de estresse.

A cama aviária é excelente material para evitar as oscilações de temperatura no interior do aviário, contribuindo para o conforto das aves (Rogeri et al., 2016). O bagaço de cana quando devidamente processado pode ser utilizado com sucesso, por ser um produto de fácil fermentação (produção de calor) quando úmido, porém apresenta predisposição para formação de torrões e crescimento de fungos (Monira et al., 2003).

Os achados da literatura reforçam que os diferentes materiais da cama aviária não influenciam o desempenho de frangos de corte, com exceção da maravalha e areia, que apresentam piora da conversão alimentar, resultando em maior mortalidade quando comparados aos demais materiais utilizados (Avila et al., 2008).

Com relação a microbiota presente nos locais amostrados, foram identificados 14 gêneros fúngicos distintos, dentre os quais, nove pertenciam a fungos filamentosos (Acremonium spp., Aspergillus spp., Bipolaris spp., Cladosporium spp., Curvularia spp., Fusarium spp., Penicillium spp., Scopulariopsis spp. e Trichoderma spp.) e 5 a fungos leveduriformes (Candida spp., Geotrichum spp., Hortaea spp., Rhodotorula spp. e Saccharomyces spp.). O gênero mais frequente foi Saccharomyces spp. com 4017 (16,6\%) UFC, seguido por Fusarium spp. com 2969 (12,2\%) UFC e Acremonium spp. com $2662(11,0 \%)$ UFC, conforme observado na Figura 1. 
Figura 1. Gêneros fúngicos identificados nos aviários de frangos de corte da Região da Zona da Mata de Alagoas.

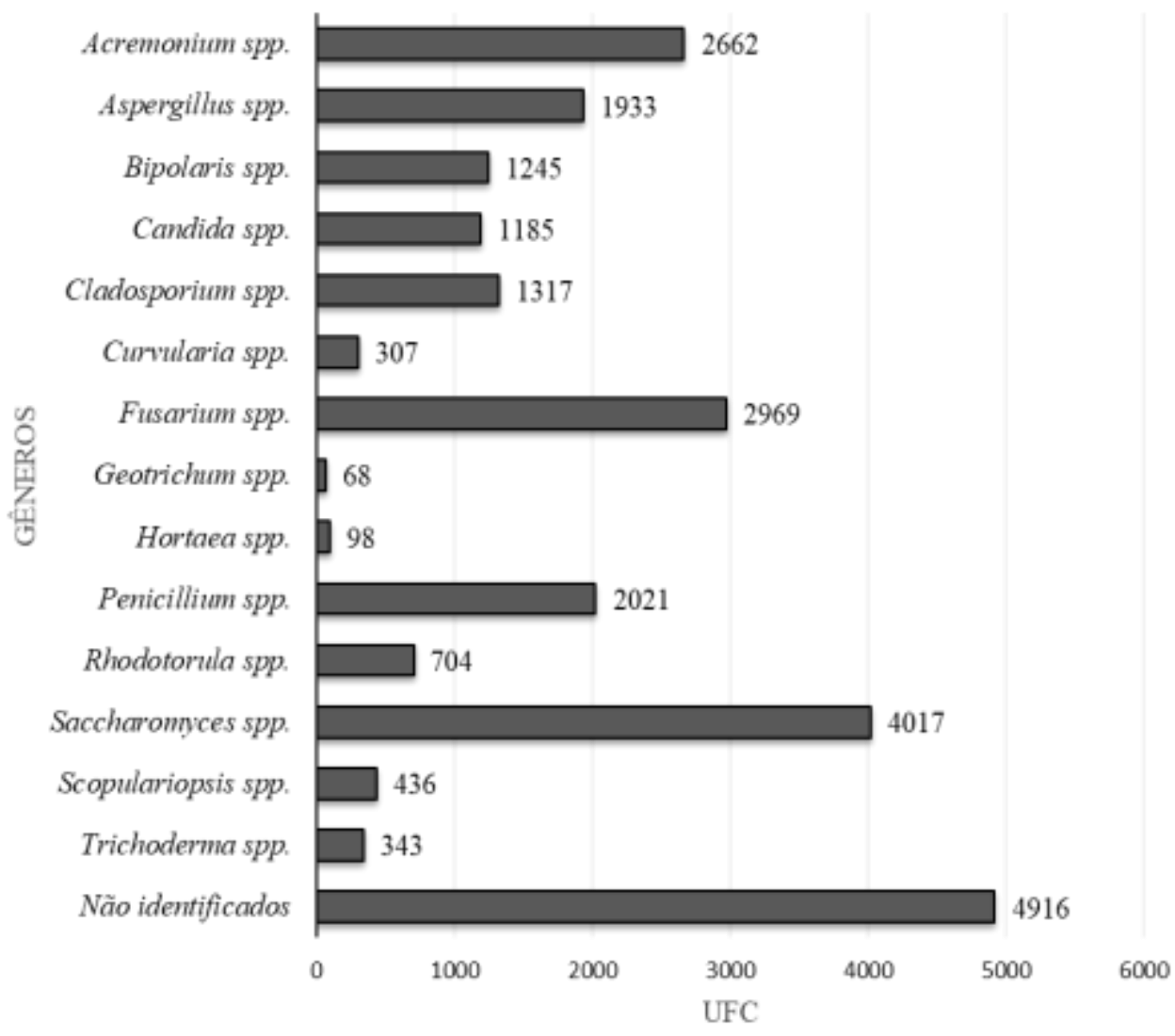

Fonte: Autores.

Esses resultados estão em concordância com a literatura e enfatizam a relevância do artigo, uma vez que Aspergillus spp., Penicillium spp. e Candida spp. estão entre os principais gêneros de fungos causadores de doenças em aves (Miragliota et al., 2002; Skóra et al., 2016; Ghaemmaghami et al., 2018; Radwan et al., 2018).

Espécies de Candida spp., em determinadas situações, ocasionam infecções no sistema digestório das aves, podendo acometer também o sistema reprodutivo, olhos e disseminar-se para outros órgãos, resultando em um quadro sistêmico (Sugiharto, 2019). Em humanos, essas leveduras podem causar desde micoses superficiais até infecções sistêmicas, especialmente em indivíduos imunocomprometidos, estando associadas a Infecções Relacionadas à Assistência à Saúde (Chen \& Jiang, 2014).

Aspergillus e Penicillium são fungos que se destacam por sua ubiquidade. A grande maioria das espécies destes gêneros são saprófitas, geralmente encontradas no ar, solo, vegetação em decomposição, sementes e grãos. Não obstante, algumas espécies são consideradas epidemiologicamente importantes por desencadearem infecções em seres humanos, denominadas de aspergilose e peniciliose (Calumby et al., 2019). Outro fato peculiar destes fungos é a produção de micotoxinas, como as aflatoxinas e as citrininas, acarretando danos a seres humanos e animais (Algabr et al., 2018).

Outro microrganismo isolado que merece atenção é Acremonium spp. Este fungo compõe a microbiota de alguns mamíferos e aves, sendo considerado patógeno oportunista de humanos, podendo causar micetomas, onicomicoses, hialohifomicoses, ceratomicoses, lesões do palato duro, meningite, artrite e doenças sistêmicas (Sidrim \& Rocha, 2010; Zaitz et al., 2010).

Na Figura 2 estão apresentados os gêneros de maior ocorrência nos diferentes substratos analisados. Os fungos mais prevalentes identificados na cama aviária pela técnica de swab de arrasto, no composto da cama, na ração e na água foram 
Saccharomyces spp. com 3409 UFC (36,7\%), Penicillium spp. com 898 UFC (9,2\%), Fusarium spp. com 1678 UFC (40,4\%), e Rhodotorula spp. com 182 UFC (17,0\%), respectivamente.

Figura 2. Prevalência de gêneros fúngicos encontrados nos diferentes substratos coletados dos aviários de frangos de corte da Região da Zona da Mata de Alagoas.

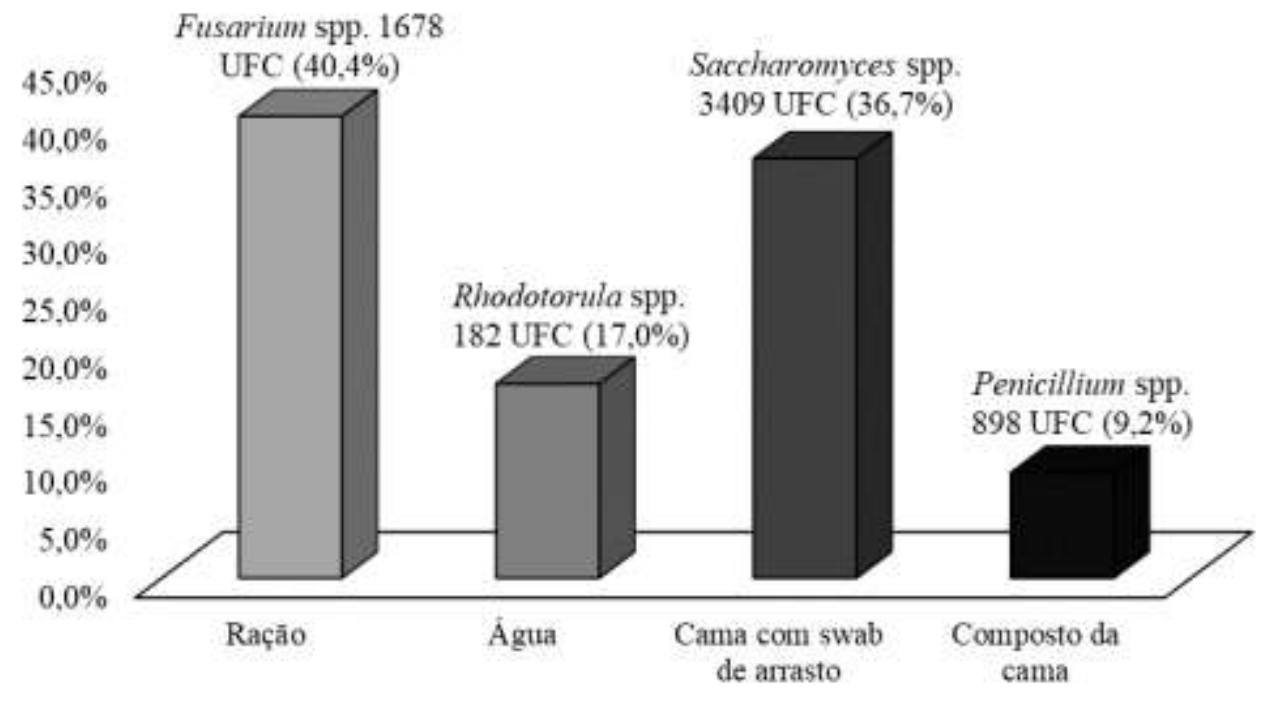

Fonte: Autores.

Os fungos Rhodotorula spp. e Saccharomyces spp. estão entre os principais microrganismos que colonizam o trato gastrintestinal de aves e suas fezes e, em consequência, ocasionam doenças aviárias e humanas. A presença destes microrganismos nas fezes perpassa para o ambiente e outros animais, podendo caracterizar uma via de transmissão zoonótica (Skóra et al., 2016).

Fungos do gênero Fusarium spp. são descritos como produtores de diversos tipos de micotoxinas, metabólitos tóxicos que podem atuar sobre o organismo animal prejudicando o seu desempenho e desenvolvendo alterações patológicas graves (Perincherry et al., 2019).

\section{Conclusão}

Em suma, verificou-se que em todos os substratos analisados havia presença de fungos com potencial patogênico para as aves e para o homem, confirmando a hipótese de que este ambiente é insalubre ao trabalhador.

Fusarium sp. e Acremonium sp. foram os gêneros de maior ocorrência entre os fungos filamentosos e Saccharomyces sp. e Candida sp. entre os leveduriformes. Esses achados tornam evidente a necessidade de criar-se protocolos mais eficientes quanto a prevenção destes agentes, de modo a manter íntegra a saúde do animal e do homem. Além disso, ressalta-se a importância de medidas de controle microbiológico, por meio de práticas de desinfecção e limpeza constante dos aviários e monitoramento frequente do ambiente.

\section{Referências}

Algabr, H. M., Alwaseai, A., Alzumir, M. A., Hassen A. A., \& Taresh, S. A. (2018). Occurrences and frequency of fungi and detection of mycotoxins on poultry rations in Yemen. Bulletin of the National Research Centre, 42(32), 1-12.

Asfaw, M., \& Dawit, D. (2017). Review on Major Fungal Disease of Poultry. British Journal of Poultry Sciences, 6 (1), 6-25.

Avila, V. S., Oliveira, U., Figueiredo, E. A. P., Costa, C. A. F., Abreu, V. M. N., \& Rosa, P. S. (2008). Avaliação de materiais alternativos em substituição à maravalha como cama de aviário. Revista Brasileira de Zootecnia, 37(2), 273-277. 
Bilgili, S. F., Hess, J. B., Donald, J., \& Fancher, B. (2010). Practical considerations for reducing the risk of pododermatitis. Aviagen Brief, 1: 1-8.

Calumby, R. J. N., Silva, J. A., Silva, D. P., Moreira, R. T. F., Araújo, M. A. S., Almeida, L. M., Grillo, L. A. M., \& Alvino, V. (2019). Isolamento e identificação da microbiota fúngica anemófila em Unidade de Terapia Intensiva. Brazilian Journal of Development, 5(10), $19708-19722$.

Chen, Z., \& Jiang, X. (2014). Microbiological safety of chicken litter or chicken litter-based organic fertilizers: a review. Agriculture, 4, 1-29. Fernandes, F. C. (2004). Poeiras em Aviários. Revista Brasileira de Medicina do Trabalho, 2(4), 253-262.

Fraga, M. E., Curvello, F. A., \& Chaves, J. P. (2009). Aspergillus em cama de frango de corte. Revista Brasileira de Medicina Veterinária, 31(3), 157-162. Ghaemmaghami, S. S., Nowroozi, H., \& Moghadam, M. T. (2018) Toxigenic fungal contamination for assessment of poultry feeds: mashed vs. pellet. Iranian Journal of Toxicology, 12(5), 5-10.

Hernandez, R., \& Cazetta, J. O. (2001). Método simples e acessível para determinar amônia liberada pela cama aviária. Revista Brasileira de Zootecnia, 30(3), 824-829.

Hernandez, R., Cazetta, J. O., \& Morais, V. M. B. (2002). Frações nitrogenadas, glicídicas e amônia liberada pela cama de frangos de corte em diferentes densidades e tempos de confinamento. Revista Brasileira de Zootecnia, 31(4), 1795-1802.

Hoog, G. S., Guarro, J., Gené, J., \& Figueras, M. J. (2000). Atlas of clinical fungi, (2a ed.), CBS, Spain. 1126p.

Lacaz, C. S., Porto, E., Martins, J. E. C., Heins-Vaccari, E. M., \& Melo, N. T. (2002). Tratado de Micologia médica; Prefácio: Bertrand Dupont. (9a ed.), Sarvier, 1104p.

Macedo, A. C., Oliveira, M. N. B., \& Souza, S. M. O. (2019). Análise microbiológica de hambúrguer de frango produzido de forma artesanal. REVETRevista Científica de Medicina Veterinária da UNICEPLAC, 5(1), 112-120.

Melo, A. M. C., Silva, T. C., Silva, A. G. S., Carneiro, R. S. R., Pontes, R. C., Souza, H. C. C., \& Albuquerque, I. M. B. (2018). Doença infecciosas das aves: revisão de literatura. Brazilian Journal of Animal and Environmental Research, 1(2), 310-314.

Meluzzi, A., \& Sirri, F. (2009). Welfare of broiler chickens. Italian Journal of Animal Science, 8(1), 161-173.

Miragliota, M. Y., Nããs, I. A., Baracho, M. S., \& Aradas, M. E. C. (2002). Qualidade do ar de dois sistemas de produção de frangos de corte com ventilação e densidade diferenciadas - estudo de caso. Engenharia Agrícola, 22(1), 1-10.

Monira, K. N., Islam, M. A., Alam, M. J., \& Wahid, M. A. (2003). Effect of litter materials on broiler performance and evaluation of manureal value of used litter in late autumn. Asian-Australasian Journal of Animal Sciences, 16(4), 555-557.

Oliveira, M. E., Oliveira, R. L. Z., Souza, M. F. L. Z., Harada, E. S., \& Tech, A. R. B. (2018). Desenvolvimento de sensores para monitoramento de ambiente aviário com ênfase em controle térmico. Brazilian Journal of Biosystems Engineering, 12(3), 234-240.

Oliveira, R. F. M., Donzele, J. L., Abreu, M. L. T., Ferreira, R. A., Vaz, R. G. M. V., \& Cella, P. S. (2006). Efeitos da temperatura e da umidade relativa sobre o desempenho e o rendimento de cortes nobres de frangos de corte de 1 a 49 dias de idade. Revista Brasileira de Zootecnia, 35(3), 797-803.

Paganini, F. J. (2004). Manejo da Cama. In: Mendes, A. A., Nããs, I. A., \& Macari, M. Produção de Frangos de Corte. São Paulo: FACTA, p. 356.

Perincherry, L., Lalak-Kańczugowska, J., \& Stępień, Ł. (2019). Fusarium-produced mycotoxins in plant-pathogen interactions. Toxins, 11(11), 664.

Radwan, I. A., Abed, A. H., \& Abdallah, A. S. (2018). Prevalence of fungal pathogens in broiler chickens and their environment. Journal of Veterinary Medical Research, 25(2), 174-181.

Riddell, R. W. (1950). Permanent stained mycological preparations obtained by slide culture. Mycologia, 42(2), 265.

Rogeri, D. A., Ernani, P. R., Mantovani, A., \& Lourenço, K. S. (2016). Composition of poultry litter in Southern Brazil. Revista Brasileira de Ciência do Solo, 40, e0140697, 1-7.

Sidrim, J. J. C., \& Rocha, M. F. G. (2010). Micologia Médica à luz de autores contemporâneos. (2a ed.), Guanabara Koogan.

Silva, I. M. M., Baliza, M., Santos, M. P., Rebouças, L. T., Rocha, E. V. S., Santos, V. A., Silva, R. M., \& Evêncio-Neto, J. (2012). Presença de Escherichia coli em fígados de frangos provenientes de matadouros avícolas. Revista Brasileira de Saúde e Produção Animal, 13(3), 694-700.

Skóra, J., Matusiak, K., Wojewódzki, P., Nowak, A., Sulyok, M., Ligocka, A., Okrasa, M., Hermann, J., \& Gutarowska, B. (2016). Evaluation of microbiological and chemical contaminants in poultry farms. International Journal of Environmental Research and Public Health, $13(2), 192$.

Staub, L., Souza, T. V., \& Ton, A. P. S. (2017). Management for reuse of avian bed. Scientific Electronic Archives, 10(5), 163-176.

Stringhini, J. H., Mogyca, N. S., Andrade, M. A., Orsine, G. F., Café, M. B., \& Borges, S. A. (2000). Efeito da qualidade do milho no desempenho de frangos de corte. Revista Brasileira de Zootecnia, 29(1), 191-198.

Sugiharto S. (2019). A review of filamentous fungi in broiler production. Annals of Agricultural Sciences, 64(1), 1-8.

Vilela, S. M. O., Mota, R. A., Santos, A. P. F., Silva, L. B. G., \& Silva, J. S. A. (2004). Surto de Aspergilose ocular em pintos de corte (Gallus gallus domesticus, Linneaus, 1758). Ciência Veterinária Tropical, 7(2-3), 145-147.

Zaitz, C., Campbell, I., Marques, A. S., Ruiz, L. R. B., \& Souza, V. M. (2010). Compêndio de micologia médica. (2a ed.), Médica e Científica. 